\title{
Antidepressant use in patients with meningioma: is there an association with tumor recurrence?
}

\author{
Karan M. Kohli, BS, ${ }^{1}$ Joshua Loewenstern, BA, ${ }^{1}$ Remi A. Kessler, BA, ${ }^{1}$ Margaret Pain, MD, ${ }^{1}$ \\ Christina A. Palmese, PhD, ${ }^{2,3}$ Joshua Bederson, MD, ${ }^{1}$ and Raj K. Shrivastava, MD ${ }^{1,4}$ \\ Departments of ${ }^{1}$ Neurosurgery, ${ }^{2}$ Neurology, ${ }^{3}$ Psychiatry, and ${ }^{4}$ Otolaryngology, Icahn School of Medicine at Mount Sinai, New \\ York, New York
}

OBJECTIVE With increasing general use of antidepressants (ADs), multiple studies have noted a small protective effect of ADs for patients with glioma, but their impact on meningioma has not been established. This study aims to evaluate the role of ADs in the context of additional clinical factors in relation to long-term risk of meningioma recurrence.

METHODS One hundred five patients with an intracranial meningioma presenting from 2011-2014 with at least 3 years of follow-up (median 4.2 years) after resection were reviewed. AD use along with demographics, tumor characteristics, and outcomes were recorded. Multivariate logistic regression was used to analyze the association of AD use with tumor recurrence, including other clinical measures significantly associated with recurrence as covariates.

RESULTS Twenty-nine patients (27.4\%) were taking ADs (27 selective serotonin reuptake inhibitors, 2 norepinephrinedopamine reuptake inhibitors) prior to tumor recurrence. Their tumors largely affected the frontal (31.0\%) or parietal lobe $(17.2 \%)$ and were located in convexity, parasagittal, or falcine (CPF) areas more frequently than skull base areas relative to the tumors of non-AD users $(p=0.035)$. $A D$ use was found to be an independent predictor of recurrence, in addition to subtotal resection and WHO grade II/III classification ( $p$ values $<0.05$ ). The median time from AD prescription to tumor recurrence was 36.6 months (interquartile range $[I Q R]=20.9-62.9$ months) and median length of AD use was 41.4 months (IQR = 24.7-62.8 months).

CONCLUSIONS AD use was an independent predictor of meningioma recurrence. This association may be due to mood or affective changes caused by tumor location in CPF regions that may be a sign of early recurrence. The finding calls attention to $A D$ use in the management of patients with meningioma, and warrants further exploration of an underlying relationship.

https://thejns.org/doi/abs/10.3171/2018.3.FOCUS17797

KEYWORDS meningioma; tumor; recurrence; antidepressants

$\mathrm{M}$ ENINGIOMAS are the most common type of CNS tumor, and account for approximately $20 \%$ of intracranial tumors. ${ }^{6,27}$ Meningiomas can be variable in size and location, and produce a variety of symptoms that include changes in vision, seizures, headaches, gait dysfunction, and hearing loss. ${ }^{24,29}$ Symptomatic meningiomas are primarily treated by resection, with or without radiation therapy. Radiotherapy is primarily used after initial resection when a subtotal resection (STR) is achieved and/or because the tumor shows a high histopathological

ABBREVIATIONS $A D=$ antidepressant; $C P F=$ convexity, parasagittal, or falcine; $F P L=$ federal poverty level; IQR = interquartile range; $m P F C=$ medial prefrontal cortex; $\mathrm{NDRI}=$ norepinephrine-dopamine reuptake inhibitor; $\mathrm{OR}=$ odds ratio; $\mathrm{SES}=$ socioeconomic status; $\mathrm{SSRI}$ = selective serotonin reuptake inhibitor; STR = subtotal resection. SUBMITTED December 30, 2017. ACCEPTED March 20, 2018. INCLUDE WHEN CITING DOI: 10.3171/2018.3.FOCUS17797. 
grade. After 5, 10, and 15 years following a total resection patients had a $6 \%, 15 \%$, and $20 \%$ risk, respectively, of having a second surgery due to recurrence, compared to $25 \%$, $54 \%$, and $84 \%$ for STRs. ${ }^{27}$

The grade of resection is correlated with the recurrence rates of meningiomas. ${ }^{1}$ Aggressive meningiomas that are classified as WHO grade II or III that have undergone a complete resection have shown lower recurrence rates compared with partial resections of slow-growing tumors. ${ }^{1}$ Adegbite et al. also noted that overall, partial resections had a higher rate of recurrence, but most patients in this scenario will have a period of time in which they are asymptomatic. ${ }^{1}$ Complete resections remain the optimal safeguard against tumor recurrence, although studies reported recurrence rates of $4 \%-15 \%$ with complete resections of slow-growing WHO grade I tumors.,27,40

Histopathological grade has been shown to strongly contribute to the risk of recurrence. WHO grade II and III meningiomas have aggressive features and potentially unpredictable outcomes. ${ }^{12}$ A study found the 5-year survival rate for WHO grade II meningiomas to be $78 \%$, compared to $44 \%$ for WHO grade III meningiomas. ${ }^{17}$ Studies have noted postresection recurrence rates for WHO grade I (benign) meningiomas to be $3 \%-14 \%$, followed by $30 \%-45 \%$ for WHO grade II (atypical), and 74\%-78\% for WHO grade III (anaplastic). ${ }^{17,25,29}$

Meningiomas can be slow growing and remain asymptomatic for long periods of time. However, for many patients with meningioma, quality of life can be drastically reduced due to both physical and psychiatric symptoms of meningiomas. A study of 79 patients with meningiomas found that $21 \%$ of patients showed only psychiatric symptoms..$^{14}$ Meningiomas, dependent on location, may present with neuropsychiatric symptoms in early stages ${ }^{41}$ For example, mood and personality disorders have been associated with frontal tumors. ${ }^{23}$ Additionally, mental status changes have been noted as primary symptoms in $18 \%$ of patients with supratentorial lesions and 5\% with infratentorial lesions..$^{23}$ Others have noted that $90 \%$ of frontal tumors produced changes in mental status and personality and other symptoms than can resemble depression, anxiety, and schizophrenia. ${ }^{30,31,41}$ Moreover, Lampl et al. found that skull base meningiomas were free of psychiatric symptoms, while $44 \%$ of convexity lesions presented with psychological symptoms (mostly depression). ${ }^{20}$ Other studies have found that apathy scores, a hallmark of depression, were highest in patients presenting with medial frontal falcine meningiomas, followed by ventral frontal tumors. ${ }^{30}$

The pharmacological management of psychiatric symptoms, notably depression, consists of treatment with antidepressants (ADs), most commonly selective serotonin reuptake inhibitors (SSRIs). SSRIs have shown to be neuroprotective against gliomas by producing a controlled environment of calcium ions that play a role in cell metabolism. ${ }^{23}$ It is believed that the influx of calcium ions for a prolonged period from SSRI administration causes disruption in the mitochondrial matrix that triggers apoptosis..$^{22,23}$ However, the role of $\mathrm{AD}$ use has been scarcely studied in meningioma patients..$^{18}$ Cea-Soriano et al., in a large analysis of 745 meningioma patients with 10,000 matched controls, found that short-term $\mathrm{AD}$ use ( $<1$ year) and overall use was asso- ciated with an increased risk of meningioma development compared to AD-free individuals. ${ }^{6}$ This finding, however, may be complicated by the possibility that the depression symptoms were early signs of meningioma. ${ }^{18}$ Studies associating SSRI use with meningioma incidence are not established, but a direct effect cannot be excluded.

A presentation of sudden depressive symptoms, often treated with ADs, may reflect an early manifestation of meningioma or an early sign of recurrence after resection that may remain undiagnosed until other, more common symptoms arise. In the present study, the postoperative behavior of meningiomas was followed to assess whether patient and tumor characteristics, most notably history of AD use, may be predictive of future meningioma recurrence.

\section{Methods}

\section{Patient Population}

The retrospective study was approved by the medical center IRB. Medical records of 112 patients who presented to our medical center from 2011 to 2014 who had at least 3 years of follow-up after primary meningioma resection were reviewed (median 4.18 years, interquartile range $[\mathrm{IQR}]=3.43-4.88$ years). Seven patients were excluded due to nonintracranial meningioma (e.g., spinal) and/or insufficient data, resulting in a final sample of 105 patients. Demographics collected included community-level socioeconomic status (SES), which was obtained by identifying the median family income of the zip code which the patient reported as their primary residence (https:// www.psc.isr.umich.edu/dis/census/Features/tract2zip/), then categorized by greater or less than $200 \%$ of the federal poverty level (FPL: https://aspe.hhs.gov/prior-hhspoverty-guidelines-and-federal-register-references) ${ }^{11}$ insurance status (public, private, or none), and access to a primary care provider. Tumor characteristics consisted of tumor volume; presence of edema; location, categorized both as 1) either skull base or in convexity, parasagittal, or falcine (CPF) areas and 2) respective lobe or skull base location; histopathological grade (WHO grade); Simpson grade of resection (denoted as complete or subtotal); and postresection recurrence (Table 1).

\section{AD Use}

Of the 105 patients included in the analysis, 29 had a recorded history of AD use (Table 2). AD name, type (e.g., SSRI or norepinephrine-dopamine reuptake inhibitor [NDRI]), dosage, and duration of use were collected. The period of use identified whether patients began AD use prior to meningioma resection only, after resection only, or continued use both prior to surgery and after. For patients with recurrence, length of time from $\mathrm{AD}$ prescription until recurrence was also recorded.

\section{Statistical Analysis}

Comparisons according to AD use groups were evaluated using Pearson's chi-square or Fisher's exact tests and Student t-tests or Mann-Whitney U-tests where appropriate. Univariate analyses of each preoperative and tumor characteristic on clinical outcomes were conducted using 
TABLE 1. Demographics and tumor characteristics of 105 patients by $A D$ use

\begin{tabular}{|c|c|c|c|}
\hline \multirow{2}{*}{$\begin{array}{l}\text { Demographic or } \\
\text { Tumor Characteristic }\end{array}$} & \multicolumn{2}{|c|}{ AD Use } & \multirow{2}{*}{$\begin{array}{c}\mathrm{p} \\
\text { value }\end{array}$} \\
\hline & Yes $(n=29)$ & No $(n=76)$ & \\
\hline Mean age $\pm S D(y r s)$ & $57.31 \pm 10.15$ & $55.04 \pm 13.11$ & 0.40 \\
\hline \multicolumn{4}{|l|}{ Sex, no. (\%) } \\
\hline Females & $23(79.3)$ & $61(80.3)$ & 0.91 \\
\hline Males & $6(20.7)$ & $15(19.7)$ & \\
\hline \multicolumn{4}{|l|}{ Race/ethnicity, no. (\%) } \\
\hline White & $17(58.6)$ & $34(44.7)$ & 0.20 \\
\hline African American & $3(10.3)$ & $10(13.2)$ & \\
\hline Hispanic & $6(20.7)$ & $7(9.2)$ & \\
\hline Asian & $1(3.4)$ & $8(10.5)$ & \\
\hline Other & $1(3.4)$ & $6(7.9)$ & \\
\hline Unknown & $1(3.4)$ & $11(14.5)$ & \\
\hline \multicolumn{4}{|l|}{$\begin{array}{l}\text { Community-level SES, } \\
\text { no. }(\%)\end{array}$} \\
\hline$<200 \% \mathrm{FPL}$ & $8(27.6)$ & $26(34.2)$ & 0.52 \\
\hline$\geq 200 \% \mathrm{FPL}$ & $21(72.4)$ & $50(65.8)$ & \\
\hline \multicolumn{4}{|l|}{ Insurance, no. (\%) } \\
\hline Public & $17(58.6)$ & $29(38.2)$ & 0.13 \\
\hline Private & $9(31.0)$ & $40(52.6)$ & \\
\hline None & $3(10.3)$ & $7(9.2)$ & \\
\hline \multicolumn{4}{|l|}{$\begin{array}{l}\text { Primary care provider, } \\
\text { no. }(\%)\end{array}$} \\
\hline Yes & $13(44.8)$ & $38(50.0)$ & 0.64 \\
\hline No & $16(55.2)$ & $38(50.0)$ & \\
\hline \multicolumn{4}{|l|}{$\begin{array}{l}\text { Tumor location-gen- } \\
\text { eral, no. }(\%)\end{array}$} \\
\hline CPF & $21(72.4)$ & $39(51.3)$ & 0.035 \\
\hline Skull base & $7(24.1)$ & $36(47.3)$ & \\
\hline \multicolumn{4}{|l|}{$\begin{array}{l}\text { Tumor location-spe- } \\
\text { cific, no. }(\%)\end{array}$} \\
\hline Frontal & $9(31.0)$ & $19(25.0)$ & 0.17 \\
\hline Parietal & $5(17.2)$ & $13(17.1)$ & \\
\hline Temporal & $3(10.3)$ & $5(6.6)$ & \\
\hline Occipital & $4(13.8)$ & $2(2.6)$ & \\
\hline $\begin{array}{l}\text { Anterior skull } \\
\text { base }\end{array}$ & $0(0)$ & $9(11.8)$ & \\
\hline $\begin{array}{l}\text { Middle skull } \\
\text { base }\end{array}$ & $4(13.8)$ & $19(25.0)$ & \\
\hline $\begin{array}{l}\text { Posterior skull } \\
\text { base }\end{array}$ & $3(10.3)$ & $8(10.5)$ & \\
\hline Intraventricular & $1(3.4)$ & $1(1.3)$ & \\
\hline \multicolumn{4}{|l|}{$\begin{array}{l}\text { Tumor location-later- } \\
\text { ality, no. (\%) }\end{array}$} \\
\hline $\mathrm{Lt}$ & $16(55.2)$ & $39(51.3)$ & 0.33 \\
\hline $\mathrm{Rt}$ & $10(34.5)$ & $34(44.7)$ & \\
\hline Both & $3(10.3)$ & $3(3.9)$ & \\
\hline $\begin{array}{l}\text { Median tumor size in } \\
\mathrm{cm}^{3}(\mathrm{IQR})\end{array}$ & $6.59(2.79-20.96)$ & $12.06(2.48-28.93)$ & 0.43 \\
\hline $\begin{array}{l}\text { Vasogenic edema } \\
\text { present, no. (\%) }\end{array}$ & $10(34.5)$ & $37(48.7)$ & 0.12 \\
\hline
\end{tabular}

CONTINUED IN NEXT COLUMN
» CONTINUED FROM PREVIOUS COLUMN

TABLE 1. Demographics and tumor characteristics of 105 patients by $A D$ use

\begin{tabular}{lrrr}
\hline \multirow{2}{*}{$\begin{array}{c}\text { Demographic or } \\
\text { Tumor Characteristic }\end{array}$} & \multicolumn{2}{c}{ AD Use } \\
\cline { 2 - 3 } \begin{tabular}{l} 
Value \\
\hline $\begin{array}{l}\text { Simpson grade, no. } \\
(\%)\end{array}$
\end{tabular} & Yes $(\mathrm{n}=29)$ & & \\
\hline GTR & $26(89.7)$ & $67(88.2)$ & 0.85 \\
\hline STR & $3(10.3)$ & $9(11.8)$ & \\
\hline WHO grade, no. (\%) & & & \\
\hline I & $22(75.9)$ & $67(88.2)$ & $0.12^{*}$ \\
\hline II & $4(13.8)$ & $8(10.5)$ & \\
\hline III & $3(10.3)$ & $1(1.3)$ & \\
\hline Recurrence, no. (\%) & $11(37.9)$ & $12(15.8)$ & 0.013 \\
\hline GTR = gross-total resection. & & \\
* Comparison of WHO grade I to WHO grade II/III. &
\end{tabular}

logistic regression models. Clinical characteristics on univariate analysis that demonstrated a $p$ value $\leq 0.10$ were included as covariates in the adjusted multivariate model. Multivariate analysis consisted of a stepwise logistic regression model. Analyses were performed using a standard statistical package (IBM SPSS, version 22.2).

\section{Results}

\section{Patient Population}

Patient demographics and tumor-specific characteristics grouped by AD use are listed in Table 1 . The overall sample had a mean age of 55.7 years, included $80 \%$ females, and consisted of $48.6 \%$ white, $12.4 \%$ African American, $12.4 \%$ Hispanic, $8.6 \%$ Asian, and $6.7 \%$ other

TABLE 2. Antidepressant use characteristics among meningioma patients

\begin{tabular}{|c|c|}
\hline AD Use Characteristic & Value \\
\hline \multicolumn{2}{|l|}{ Type, no. (\%) } \\
\hline SSRI & 27 (93.1) \\
\hline NDRI & $2(6.9)$ \\
\hline \multicolumn{2}{|l|}{ Period of use, no. (\%) } \\
\hline Before resection & $14(48.3)$ \\
\hline Before resection only & $2(6.9)$ \\
\hline After resection & 27 (93.1) \\
\hline After resection only & $15(51.7)$ \\
\hline Both before and after & $12(41.4)$ \\
\hline \multicolumn{2}{|c|}{ Mos from AD start until surgery $(n=14)$} \\
\hline Median (IQR) & $16.0(5.0-40.2)$ \\
\hline \multicolumn{2}{|c|}{ Mos until AD start if after surgery $(n=15)$} \\
\hline Median (IQR) & $21.1(3.3-29.3)$ \\
\hline \multicolumn{2}{|l|}{ Total mos of use $(n=29)$} \\
\hline Median (IQR) & $41.4(24.7-62.8)$ \\
\hline \multicolumn{2}{|c|}{ Mos of use until recurrence $(n=11)$} \\
\hline Median (IQR) & $36.6(20.9-62.9)$ \\
\hline
\end{tabular}


TABLE 3. Univariate and multivariate analysis of patient and tumor characteristics on meningioma recurrence

\begin{tabular}{|c|c|c|c|c|c|c|}
\hline \multirow[b]{2}{*}{ Characteristic } & \multicolumn{3}{|c|}{ Univariate } & \multicolumn{3}{|c|}{ Multivariate } \\
\hline & OR & $95 \% \mathrm{Cl}$ & p Value & OR & $95 \% \mathrm{Cl}$ & $p$ Value \\
\hline AD use & 3.26 & $1.23-8.61$ & 0.019 & 3.42 & $1.03-11.36$ & 0.045 \\
\hline Present with gait dysfunction & 2.59 & $0.92-7.28$ & 0.065 & - & - & - \\
\hline Sex (males vs females) & 2.83 & $1.01-8.00$ & 0.045 & - & - & - \\
\hline Current smoker & 4.11 & $0.94-17.92$ & 0.068 & - & - & - \\
\hline Simpson grade of resection (STR vs GTR) & 6.74 & $1.89-23.94$ & 0.004 & 11.90 & $2.72-52.63$ & 0.001 \\
\hline Preop radiation treatment & 12.15 & $1.20-123.08$ & 0.032 & - & - & - \\
\hline WHO grade (I vs II/III) & 14.12 & $4.17-47.80$ & $<0.001$ & 17.24 & $4.46-66.67$ & $<0.001$ \\
\hline
\end{tabular}

$\mathrm{Cl}=$ confidence interval.

race or ethnicity, with $11.4 \%$ unknown. In the study population, $32.4 \%$ lived in a poor community, $46.7 \%$ had private insurance (43.8\% public, $9.5 \%$ noninsured), and about half $(48.6 \%)$ had a primary care provider documented. Meningiomas were located mostly (57.1\%) in CPF regions (41.0\% in the skull base, $1.9 \%$ intraventricular). Tumors were more specifically located in frontal (26.7\%) and middle skull base regions $(21.9 \%)$. The median tumor size was 9.56 $\mathrm{cm}^{3}$, with $44.8 \%$ of tumors exhibiting vasogenic edema. Intraoperatively, the majority of tumors $(89.5 \%)$ were fully resected and $85.7 \%$ were classified as WHO grade I. During a minimum of 3 years of postoperative follow-up, 23 meningiomas (21.9\%) recurred.

Patients did not significantly differ in age, sex, or race distributions, community-level SES, insurance status, or use of a primary care provider by AD use ( $p$ values $>0.05$ ). More meningiomas were located in CPF regions in the AD use group $(72.4 \%$ vs $51.3 \%, \mathrm{p}=0.035)$. However, there were no differences in specific tumor location or laterality ( $p=0.17$ and 0.33 , respectively). Median tumor size, presence of vasogenic edema, grade of resection, and distribution in WHO grade also did not differ between AD use groups ( $\mathrm{p}$ values $>0.05$ ). Postoperatively, patients using ADs experienced significantly more tumor recurrences $(37.9 \%)$ than those not taking an AD (15.8\%, $\mathrm{p}=0.013)$.

\section{AD Use}

Specific AD use patterns are shown in Table 2. Of the 29 patients with a history of AD use, most (93.1\%) were prescribed an SSRI. The majority of patients (93.1\%) were taking an AD after resection (44\% [12/27] of those also prior to surgery) while $2(6.9 \%)$ took an $\mathrm{AD}$ prior to resection only and $15(51.7 \%)$ began AD use after. Of those starting an $\mathrm{AD}$ prior to surgery, median length of use until surgery was 16.0 months. For the remaining patients, a median of 21.1 months passed before AD prescription. Overall, patients were taking an $\mathrm{AD}$ for a median total length of 41.4 months. The median length of time from starting an $\mathrm{AD}$ until tumor recurrence was 36.6 months.

\section{Associations With Tumor Recurrence}

On univariate analysis, AD use was significantly associated with meningioma recurrence (odds ratio [OR] 3.26, $\mathrm{p}=0.019)$ in addition to male sex, preoperative radiation treatment, subtotal grade of tumor resection, and WHO II or III tumor grade ( $\mathrm{p}$ values $<0.05$; Table 3 ). Presentation with gait dysfunction and current smoking status were also found to be associated with meningioma recurrence at a trend level ( $\mathrm{p}=0.065$ and 0.068 , respectively) Multivariate analysis demonstrated that, in addition to an STR and WHO II or III tumor grade ( $p \leq 0.001)$, AD use was a significant independent predictor of meningioma recurrence $(\mathrm{OR} 3.42, \mathrm{p}=0.045)$.

As depicted in Fig. 1, within patients with WHO grade I tumors, there were no significant differences in recurrences between those located in $\mathrm{CPF}$ or skull base regions $(p=0.77)$, while $77 \%$ of tumors located in CPF regions recurred relative to $33 \%$ of skull base located tumors within patients with WHO grade II or III meningiomas only, although the difference was not significant $(p=0.21)$. Similarly, within patients without a history of AD use, there were no differences in tumor recurrence between CPF or skull base regions $(p=0.76)$, while observationally there was a greater percentage of recurrence in $\mathrm{CPF}$ regions (43\%) compared to the skull base (29\%) among those patients using an $\mathrm{AD}$, although the difference was not statistically significant (Fig. 2).

Patients using an AD who had a recurrence after resection are detailed in Table 4. These patients were 73\% female and ranged from 36-66 years at the time of resection. A large proportion $(45 \%)$ had WHO grade II or III tumors. Specifically, 3 of the 4 total patients in the overall sample with WHO grade III tumors were using an AD and later experienced tumor recurrence. Length of $\mathrm{AD}$ use ranged from 1.9-10.4 years and meningiomas recurred as short as 6 months up until more than 13 years after initial resection.

\section{Discussion}

The present study demonstrated that a WHO grade II/ III meningioma was an independent predictor of recurrence. Patients with a WHO grade II/III tumor were more than 17 times more likely to have a recurrence compared to those with WHO grade I histopathology ( $p<0.001$, Table 3). About $40 \%$ of WHO grade II and $75 \%$ of WHO grade III tumors have been found to recur in past studies compared to approximately $10 \%$ of WHO grade I tumors. ${ }^{12,17,25,29,36}$ These past findings compare to $58 \%$ and 

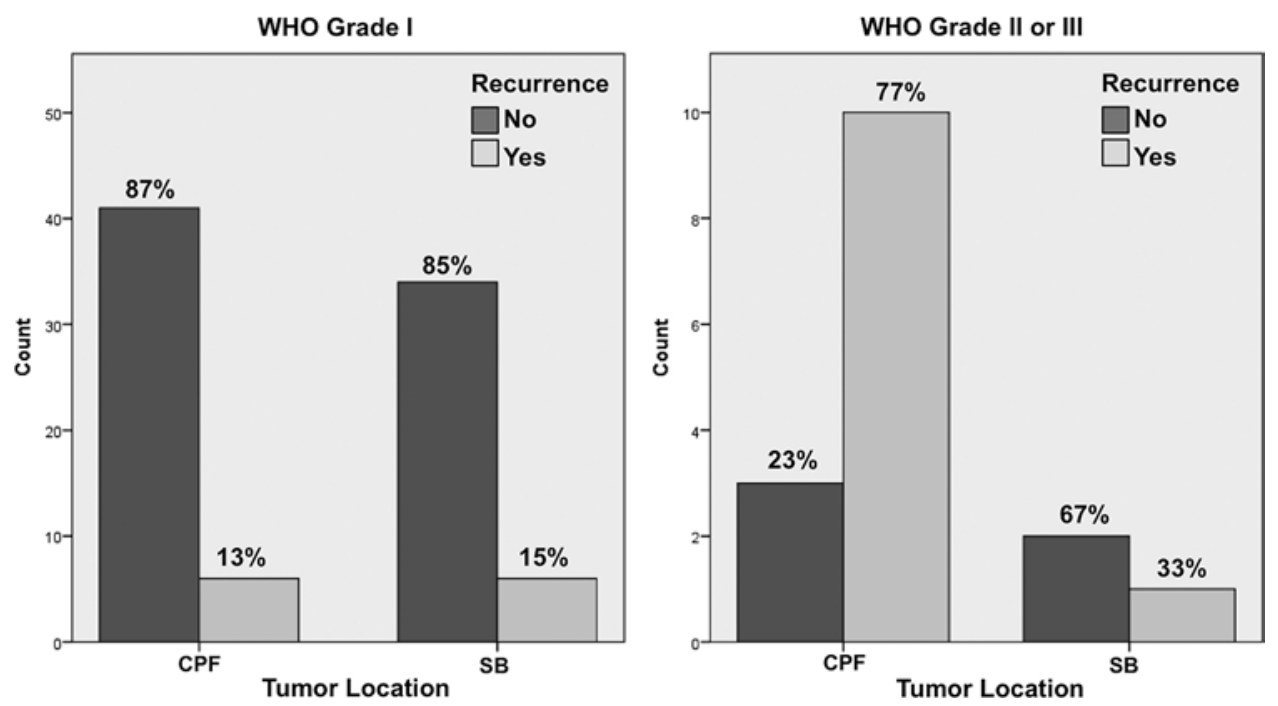

FIG. 1. Comparison of meningioma recurrence rate by CPF or skull base $(\mathrm{SB})$ tumor location for $\mathrm{WHO}$ grade I $(\mathrm{n}=87 ; 47 \mathrm{CPF}$ vs $40 \mathrm{SB}$ ) and WHO grade II and III ( $\mathrm{n}=16$; $13 \mathrm{CPF}$ vs $3 \mathrm{SB}$ ) tumors.

$100 \%$ of patients in the current sample with WHO grade II and III, respectively, who had a recurrence after resection, while only $13 \%$ of WHO grade I tumors recurred.

The degree of meningioma resection is also known to be a predictor of the risk of recurrence. ${ }^{17,26,32} \mathrm{In}$ the present sample, STRs were 12 times more likely to recur relative to complete resections. This is comparable to past work demonstrating partial resections with about a 5-times higher risk of recurrence at 5 years and 3-times higher risk at 15 years compared to complete resection. ${ }^{27}$ Meningiomas may only be partially resected due to proximity of the tumor to crucial vasculature structures, or due to difficulty of tumor access. ${ }^{26,27}$ However, even a complete removal of a WHO grade II or III meningioma is unreliable because cells can be unnoticed dependent on location. ${ }^{17}$ The aggressive nature of the higher histological grade tumors causes residual cells to multiply, becoming problematic in the following years after surgery.

In addition to histopathological grade and resection grade, interestingly, AD use was found to be an independent predictor of recurrence. AD use has been correlated with the risk of developing a meningioma in a prior large study, ${ }^{6}$ but a paucity of past studies have investigated this relationship. In this analysis, Cea-Soriano et al. found an association between both overall and short-term $(<1$ year) $\mathrm{AD}$ use and meningioma incidence in a nationwide sample of almost 750 patients with meningioma and 10,000 matched control cases. Patients with a meningioma were 1.5-2 times as likely to be using ADs compared with ageand sex-matched controls. While the study did not evaluate
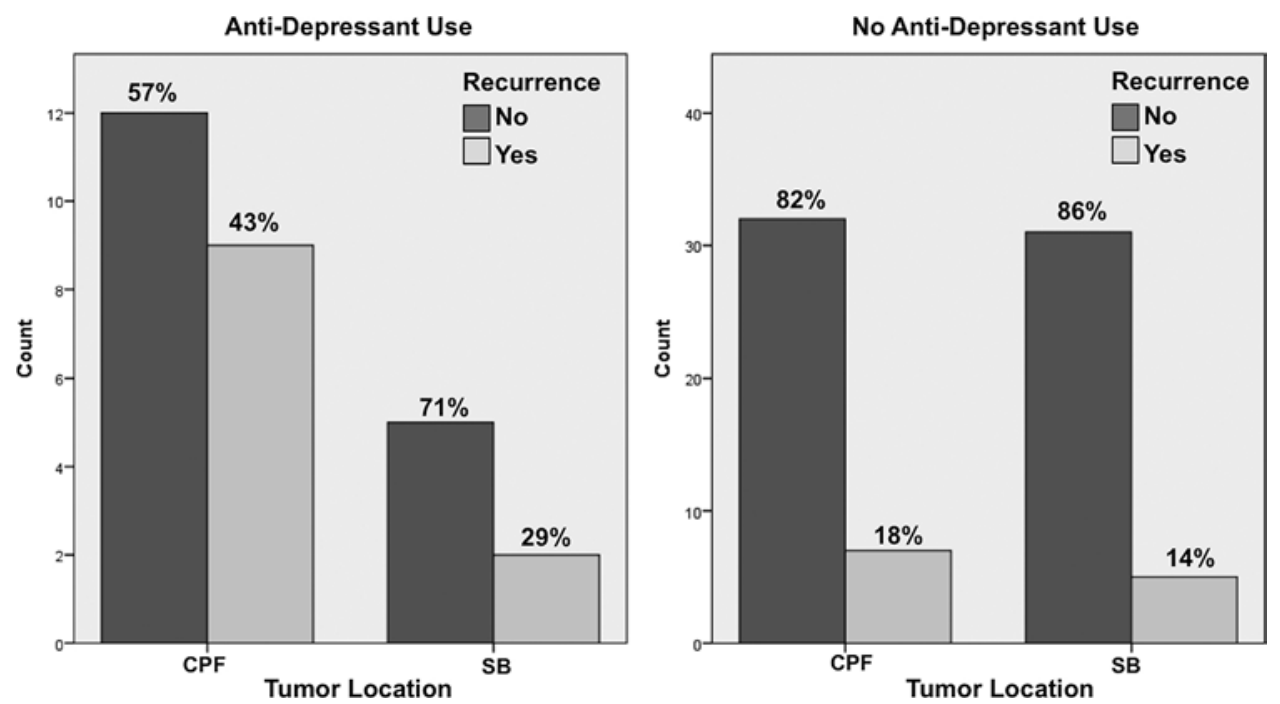

FIG. 2. Comparison of meningioma recurrence rate by CPF or skull base (SB) tumor location for patients with a history of $A D$ use $(n=28 ; 21$ CPF vs 7 SB) and without AD use ( $n=75 ; 39$ CPF vs 36 SB). 
TABLE 4. Characteristics of patients with current or past history of AD use who had a meningioma recurrence after resection

\begin{tabular}{cccccccc}
\hline $\begin{array}{c}\text { Case } \\
\text { No. }\end{array}$ & $\begin{array}{c}\text { Age (yrs), } \\
\text { Sex }\end{array}$ & $\begin{array}{c}\text { WHO } \\
\text { Grade }\end{array}$ & AD Type & $\begin{array}{c}\text { Dosage } \\
(\mathrm{mg})\end{array}$ & Period of AD Use & $\begin{array}{c}\text { Length of AD } \\
\text { Use (yrs) }\end{array}$ & $\begin{array}{c}\text { Time From Resection } \\
\text { Until Recurrence (yrs) }\end{array}$ \\
\hline 1 & $62, \mathrm{~F}$ & I & Sertraline & 100 & Postresection & 7.7 & 13.2 \\
\hline 2 & $40, \mathrm{~F}$ & I & Sertraline & 100 & Postresection & 1.9 & 3.4 \\
\hline 3 & $36, \mathrm{~F}$ & I & Escitalopram & 20 & Postresection & 2.4 & 5.5 \\
\hline 4 & $39, \mathrm{~F}$ & I & Sertraline & 100 & Preresection & 10.4 & 3.4 \\
\hline 5 & $57, \mathrm{~F}$ & I & Citalopram & 20 & Pre- and postresection & 5.9 & 4.5 \\
\hline 6 & $66, \mathrm{~F}$ & I & Paroxetine & 40 & Postresection & 3.6 & 0.5 \\
\hline 7 & $53, \mathrm{~F}$ & II & Fluoxetine & 20 & Pre- and postresection & 2.9 & 3.1 \\
\hline 9 & $63, \mathrm{~F}$ & II & Sertraline & 25 & Postresection & 3.4 & 1.4 \\
\hline 10 & $57, \mathrm{M}$ & III & Escitalopram & 5 & Pre- and postresection & 4.6 & 2.3 \\
\hline 11 & $64, \mathrm{M}$ & III & Bupropion & 150 & Postresection & 2.7 & 0.8 \\
\hline
\end{tabular}

recurrence rates, the results demonstrated a clear association between $\mathrm{AD}$ use and meningioma incidence relative to controls. ${ }^{6}$

SSRI use, however, has been shown to be neuroprotective against the occurrence of gliomas. ${ }^{5,22,23}$ Levkovitz et al. found that SSRI use caused concentration-dependent apoptosis and DNA fragment degradation in glioma cells. Even though SSRI use has been shown to be neuroprotective against gliomas, in contrast, our study shows that AD use was associated with increased recurrence rates. SSRI use impacts the CNS by increasing the transmission of serotonin, which can promote mitosis and proliferation in an array of cancer types..$^{21,35}$ Because mitotic activity is a key predictor of meningioma recurrence risk, SSRI use may possibly have a role in expediting this process. Furthermore, $\mathrm{AD}$ use has been linked to an increase risk for other cancer types, including ovarian and breast cancer., ${ }^{9}$ Cotterchio et al. found that greater than 2-year use of paroxetine was associated with a 7-fold increase in breast cancer incidence. ${ }^{9}$ Similarly, a case-control analysis by Harlow et al. noted that $\mathrm{AD}$ use was associated with twice the risk of ovarian cancer development, ${ }^{15}$ but more recent studies have not replicated this finding. ${ }^{8,28,38}$ Thus, it is possible that AD use may similarly have a larger role in the clinical outcomes of meningiomas than initially expected.

Psychiatric dysfunction may be an early, or only, symptom in the presentation of a meningioma. ${ }^{18,24}$ Past studies have noted that higher incidences of depression were associated with meningioma location or extent of edema, likely through pressure on specific brain regions. ${ }^{20,24,30}$ However, the present study did not find any difference between peritumoral edema and $\mathrm{AD}$ use $(\mathrm{p}=0.12)$ or tumor size $(\mathrm{p}$ $=0.43$ ). It is possible that these findings suggest that vasogenic edema alone might cause depression, but could contribute to depressive symptoms if located near mood regulation pathways.

In regard to tumor location, prior studies have found that meningiomas located in frontal lobe or anterior regions were associated with higher depressive symptoms. . $^{13,16,20,39}$ Yakhmi et al. concluded in multiple cases that frontal meningiomas had a higher risk of developing depression symptoms, and Hendrix et al. recently noted an increase in depression scale scores for tumors located at the frontal lobe relative to nonfrontal locations. ${ }^{16,39}$ The present study, in contrast, although not assessing depression symptoms directly, did not find a specific difference in AD use between frontal- or anterior-located meningiomas $(p=0.17)$. However, tumors located in CPF regions were found to be associated with greater AD use relative to tumors in skull base regions $(p=0.035)$. Seventy-three percent of patients using ADs had meningiomas located in CPF regions compared to about half of non-AD users. Previous work has found that patients with skull base tumors showed decreased signs of psychiatric symptoms compared to convexity meningiomas, ${ }^{20}$ and others reported cases of meningiomas causing early depression symptoms without typical neurological symptoms. . $^{14,37,41}$

While there is overlap between CPF and frontal or anterior regions, past work has delineated, to an extent, what symptoms are associated with specific tumor locations..$^{10,24,40}$ For example, convexity meningiomas are associated with memory and emotional dysfunction. ${ }^{14,41}$ The falcine and parasagittal meningiomas can cause pressure on the medial aspect of the frontal lobe. Primate studies have demonstrated that damage to the medial frontal lobe decreases interest in activity. ${ }^{30,34}$ Pressure on limbic structures such as the anterior cingulate gyrus may play an important role in motivation. ${ }^{10,30}$ Compression of this structure may cause reduction in motivation, emotion regulation, and executive function. ${ }^{4,10}$ Furthermore, functional imaging has implicated the medial prefrontal cortex (mPFC), a region also located in the proximity of parasagittal and falcine areas, with processing of negative emotional stimuli. ${ }^{2,3}$ Treatment with an AD has been shown to modulate activation of the mPFC during negative stimuli appraisal. ${ }^{3}$ Moreover, tumors of parasagittal regions involving pericallosal areas can affect integral limbic structures that contribute to emotion regulation. ${ }^{33}$ Thus, CPF tumors, relative to skull base-located tumors, may lead to a disruption of key cortical-subcortical networks involved in mood and emotion regulation. ${ }^{20,33}$

Given that AD use was found to independently predict 


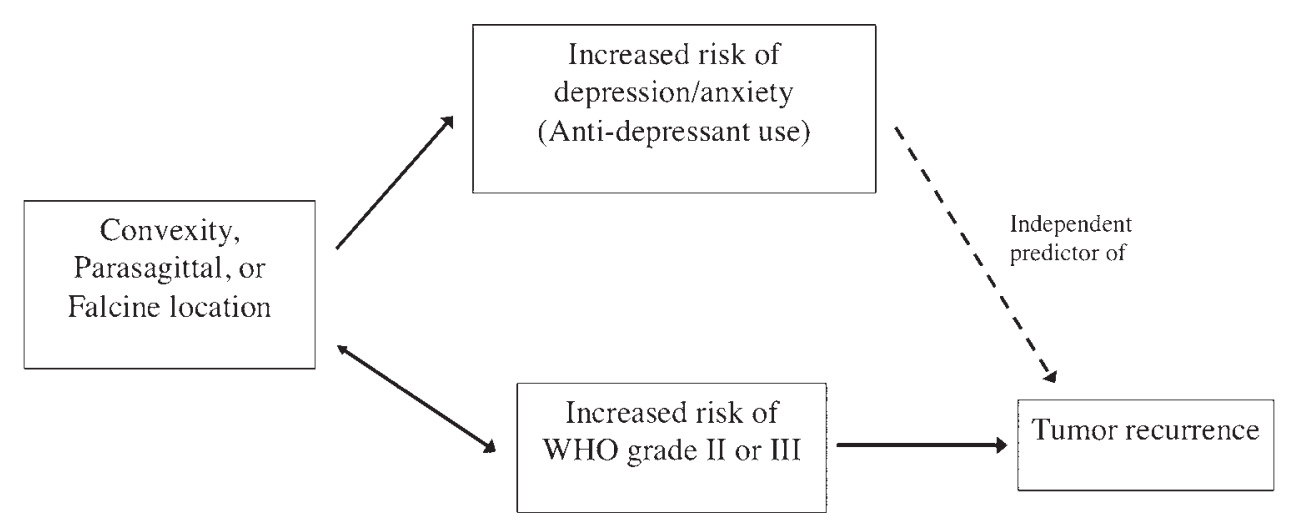

FIG. 3. Proposed model of $\mathrm{CPF}$ meningioma location risk for $\mathrm{AD}$ use, WHO histopathological grade, and tumor recurrence.

the risk of meningioma recurrence, a proposed mechanism for this association is modeled in Fig. 3. It has been well established, both in the present study and past work, that $\mathrm{CPF}$-located tumors are associated with more aggressive WHO grade II or III histopathology relative to skull base-located tumors. ${ }^{12,30,41}$ Similarly, WHO grade II or III tumors are subsequently correlated with increased rates of recurrence, which was replicated in the present study. As depicted in Fig. 1, there is a disparity among the frequency of WHO grade II or III tumors in CPF regions compared to skull base regions ( $\mathrm{p}=0.042)$ and, further, it is the CPFlocated tumors that appear to drive the increased recurrence rate $(77 \%)$ noted in the WHO grade II or III tumors, although a statistically significant difference could not be established.

However, CPF-located tumors were also found to be associated with AD use, which may represent a risk of depression or other affective symptoms, likely through mass effect disruption of underlying neural processes, and can separately predict an increased risk of meningioma recurrence (Fig. 3). Figure 2 demonstrates a significant difference between the AD use among patients with either CPF or skull base tumors $(p=0.035)$. Similar to the pattern seen with histopathological grade, the CPF-located tumors appear to most strongly affect the increased recurrence rate noted in patients with AD use relative to patients with skull base-located tumors ( $43 \%$ vs $29 \%$ ), but a significant statistical difference was not reached due to the small group size, while there was no difference in recurrence rates among patients without AD use. Thus, it is possible CPF versus skull base tumor location can be a notable determinant of both risk of $\mathrm{AD}$ use (and therefore depression symptoms) and the likelihood of more aggressive tumor grade, which subsequently would increase the risk of recurrence. Larger studies are needed to investigate this proposed relationship further.

Patients with a current or past history of AD use who experienced a recurrence are described in Table 4. A large proportion of patients had WHO grade II or III tumors, which is consistent with past work showing higher risk of recurrence with high-grade meningiomas.,17,29 Interestingly, 3 of the only 4 patients in the overall sample with a WHO grade III meningioma were not only using an AD but also had a meningioma recurrence. Of note, $91 \%$ of overall patients began AD use or continued after menin- gioma resection, which may indicate early signs of meningioma growth prior to typical neurological presentation, although reactive depressive symptoms to the diagnosis may have a role. The tumors recurred in 6 months to 8 years for WHO grade II or III types and in about $2-13$ years in WHO grade I type tumors after resection. This finding is comparable to those in past studies demonstrating a mean length of time to recurrence of 7.5 years for WHO grade I and 2-4 years for WHO grade II or III meningiomas. ${ }^{17,19}$ With little past work on the physiological impact of highgrade tumors and depression, it is possible that their recurrence in certain areas of cortex can potentially cause disruptions of mood pathways.

The present study contains several important limitations. First, one is cautioned that the findings regarding depression and psychiatric symptoms are concluded from retrospective $\mathrm{AD}$ prescription and length of use, not from a formal diagnosis of depression. While the relatively small size of the present sample can be attributed to the specific exclusion criteria, chiefly a minimum of 3 years of followup, patient characteristics, patterns of AD use, and clinical outcomes were more closely monitored than in related past studies. Due to this limitation, the study potentially missed capturing earlier effects on recurrence in patients with fewer than 3 years of follow-up after resection. Thus, larger prospective studies are needed to specifically investigate depression history and AD use in the context of short- and long-term risk for meningioma recurrence and other clinical outcomes.

\section{Conclusions}

Current or prior history of AD use was found to independently predict the risk of meningioma recurrence after resection, even controlling for patient and tumor characteristics including histopathological grade and extent of resection. Specifically, CPF-located tumors were associated with higher use of ADs relative to skull base-located meningiomas and increased frequency of WHO grade II or III histological subtype. Thus, in addition to the wellestablished association of CPF location and more aggressive pathology, we proposed that $\mathrm{CPF}$-located tumors may also be related to depression symptoms, possibly due to location-specific disruption of underlying mood regulation circuits, which can independently predict the risk of recur- 
rence. However, given the increased prevalence of AD use, further studies are warranted to investigate the possible relationship between $\mathrm{AD}$ use, depression symptoms, and the risk for postresection recurrence in order to determine the best management of patients with meningioma.

\section{References}

1. Adegbite AB, Khan MI, Paine KW, Tan LK: The recurrence of intracranial meningiomas after surgical treatment. J Neurosurg 58:51-56, 1983

2. Anand A, Li Y, Wang Y, Wu J, Gao S, Bukhari L, et al: Activity and connectivity of brain mood regulating circuit in depression: a functional magnetic resonance study. Biol Psychiatry 57:1079-1088, 2005

3. Benedetti F, Radaelli D, Bernasconi A, Dallaspezia S, Colombo C, Smeraldi E: Changes in medial prefrontal cortex neural responses parallel successful antidepressant combination of venlafaxine and light therapy. Arch Ital Biol 147:8393, 2009

4. Bush G, Luu P, Posner MI: Cognitive and emotional influences in anterior cingulate cortex. Trends Cogn Sci 4:215-222, 2000

5. Caudill JS, Brown PD, Cerhan JH, Rummans TA: Selective serotonin reuptake inhibitors, glioblastoma multiforme, and impact on toxicities and overall survival: the mayo clinic experience. Am J Clin Oncol 34:385-387, 2011

6. Cea-Soriano L, Wallander MA, García Rodríguez LA: Epidemiology of meningioma in the United Kingdom. Neuroepidemiology 39:27-34, 2012

7. Ciobanu AM, Lisievici MG, Coman TC, Ciubotaru GV, Drăghia A, Drăghia F, et al: Giant wing sphenoid meningioma with principal manifestation depression. Rom J Morphol Embryol 50:713-717, 2009

8. Coogan PF, Rosenberg L, Palmer JR, Strom BL, Stolley PD, Zauber AG, et al: Risk of ovarian cancer according to use of antidepressants, phenothiazines, and benzodiazepines (United States). Cancer Causes Control 11:839-845, 2000

9. Cotterchio M, Kreiger N, Darlington G, Steingart A: Antidepressant medication use and breast cancer risk. Am J Epidemiol 151:951-957, 2000

10. Cummings JL: Frontal-subcortical circuits and human behavior. Arch Neurol 50:873-880, 1993

11. DeNoble AE, Hall KS, Xu X, Zochowski MK, Piehl K, Dalton VK: Receipt of prescription contraception by commercially insured women with chronic medical conditions. Obstet Gynecol 123:1213-1220, 2014

12. Durand A, Labrousse F, Jouvet A, Bauchet L, Kalamaridès M, Menei P, et al: WHO grade II and III meningiomas: a study of prognostic factors. J Neurooncol 95:367-375, 2009

13. Goebel S, Mehdorn HM: Development of anxiety and depression in patients with benign intracranial meningiomas: a prospective long-term study. Support Care Cancer 21:1365-1372, 2013

14. Gupta RK, Kumar R: Benign brain tumours and psychiatric morbidity: a 5-years retrospective data analysis. Aust $\mathbf{N} \mathbf{Z}$ J Psychiatry 38:316-319, 2004

15. Harlow BL, Cramer DW: Self-reported use of antidepressants or benzodiazepine tranquilizers and risk of epithelial ovarian cancer: evidence from two combined case-control studies (Massachusetts, United States). Cancer Causes Control 6:130-134, 1995

16. Hendrix P, Hans E, Griessenauer CJ, Simgen A, Oertel J, Karbach J: Neurocognitive status in patients with newlydiagnosed brain tumors in good neurological condition: the impact of tumor type, volume, and location. Clin Neurol Neurosurg 156:55-62, 2017

17. Jääskeläinen J, Haltia M, Servo A: Atypical and anaplastic meningiomas: radiology, surgery, radiotherapy, and outcome. Surg Neurol 25:233-242, 1986
18. Kessler RA, Loewenstern J, Kohli K, Shrivastava RK: Is psychiatric depression a presenting neurologic sign of meningioma? A critical review of the literature with causative etiology. World Neurosurg 112:64-72, 2018

19. Klinger DR, Flores BC, Lewis JJ, Hatanpaa K, Choe K, Mickey B, et al: Atypical meningiomas: recurrence, reoperation, and radiotherapy. World Neurosurg 84:839-845, 2015

20. Lampl Y, Barak Y, Achiron A, Sarova-Pinchas I: Intracranial meningiomas: correlation of peritumoral edema and psychiatric disturbances. Psychiatry Res 58:177-180, 1995

21. Lesurtel M, Graf R, Aleil B, Walther DJ, Tian Y, Jochum W, et al: Platelet-derived serotonin mediates liver regeneration. Science 312:104-107, 2006

22. Levkovitz Y, Gil-Ad I, Zeldich E, Dayag M, Weizman A: Differential induction of apoptosis by antidepressants in glioma and neuroblastoma cell lines: evidence for p-c-Jun, cytochrome c, and caspase-3 involvement. J Mol Neurosci 27:29-42, 2005

23. Liu KH, Yang ST, Lin YK, Lin JW, Lee YH, Wang JY, et al: Fluoxetine, an antidepressant, suppresses glioblastoma by evoking AMPAR-mediated calcium-dependent apoptosis. Oncotarget 6:5088-5101, 2015

24. Madhusoodanan S, Opler MG, Moise D, Gordon J, Danan $\mathrm{DM}$, Sinha A, et al: Brain tumor location and psychiatric symptoms: is there any association? A meta-analysis of published case studies. Expert Rev Neurother 10:1529-1536, 2010

25. Maier H, Öfner D, Hittmair A, Kitz K, Budka H: Classic, atypical, and anaplastic meningioma: three histopathological subtypes of clinical relevance. J Neurosurg 77:616-623, 1992

26. Marks SM, Whitwell HL, Lye RH: Recurrence of meningiomas after operation. Surg Neurol 25:436-440, 1986

27. Mirimanoff RO, Dosoretz DE, Linggood RM, Ojemann RG, Martuza RL: Meningioma: analysis of recurrence and progression following neurosurgical resection. J Neurosurg 62:18-24, 1985

28. Moorman PG, Berchuck A, Calingaert B, Halabi S, Schildkraut JM: Antidepressant medication use for and risk of ovarian cancer. Obstet Gynecol 105:725-730, 2005

29. Nowak A, Dziedzic T, Krych P, Czernicki T, Kunert P, Marchel A: Benign versus atypical meningiomas: risk factors predicting recurrence. Neurol Neurochir Pol 49:1-10, 2015

30. Peng Y, Shao C, Gong Y, Wu X, Tang W, Shi S: Relationship between apathy and tumor location, size, and brain edema in patients with intracranial meningioma. Neuropsychiatr Dis Treat 11:1685-1693, 2015

31. Schwartz AC, Afejuku A, Garlow SJ: Bifrontal meningioma presenting as postpartum depression with psychotic features. Psychosomatics 54:187-191, 2013

32. Simpson D: The recurrence of intracranial meningiomas after surgical treatment. J Neurol Neurosurg Psychiatry 20:22-39, 1957

33. Tekin S, Cummings JL: Frontal-subcortical neuronal circuits and clinical neuropsychiatry: an update. J Psychosom Res 53:647-654, 2002

34. Thaler D, Chen YC, Nixon PD, Stern CE, Passingham RE: The functions of the medial premotor cortex. I. Simple learned movements. Exp Brain Res 102:445-460, 1995

35. Tutton PJM, Barkla DH: The influence of serotonin on the mitotic rate in the colonic crypt epithelium and in colonic adenocarcinoma in rats. Clin Exp Pharmacol Physiol 5:91-94, 1978

36. Violaris K, Katsarides V, Karakyriou M, Sakellariou P: Surgical outcome of treating grades II and III meningiomas: a report of 32 cases. Neurosci J 2013:706481, 2013

37. Wellisch DK, Kaleita TA, Freeman D, Cloughesy T, Goldman J: Predicting major depression in brain tumor patients. Psychooncology 11:230-238, 2002 
38. Wu CS, Lu ML, Liao YT, Lee CT, Chen VC: Ovarian cancer and antidepressants. Psychooncology 24:579-584, 2015

39. Yakhmi S, Sidhu BS, Kaur J, Kaur A: Diagnosis of frontal meningioma presenting with psychiatric symptoms. Indian J Psychiatry 57:91-93, 2015

40. Yamasaki F, Yoshioka H, Hama S, Sugiyama K, Arita K, Kurisu K: Recurrence of meningiomas. Cancer 89:11021110,2000

41. Zivković N, Marković M, Spaić M: Convexity meningioma associated with depression: a case report. Srp Arh Celok Lek 142:586-588, 2014

\section{Disclosures}

The authors report no conflict of interest concerning the materi- als or methods used in this study or the findings specified in this paper.

\section{Author Contributions}

Conception and design: Shrivastava, Kohli, Loewenstern, Pain, Palmese, Bederson. Acquisition of data: Kohli, Loewenstern, Pain. Analysis and interpretation of data: Shrivastava, Kohli, Loewenstern, Kessler, Palmese. Drafting the article: Shrivastava, Kohli, Loewenstern, Kessler. Critically revising the article: all authors. Reviewed submitted version of manuscript: all authors. Approved the final version of the manuscript on behalf of all authors: Shrivastava. Statistical analysis: Kohli, Loewenstern. Study supervision: Shrivastava, Loewenstern, Pain, Palmese, Bederson.

\section{Correspondence}

Raj K. Shrivastava: Mount Sinai Health System, New York, NY. raj.shrivastava@mountsinai.org. 